\title{
Spotlight on hypertension in the Indian subcontinent
}

\author{
Sunil K Nadar ${ }^{1}$ \\ Received: 5 June 2019 / Accepted: 21 June 2019 / Published online: 3 July 2019 \\ (c) Springer Nature Limited 2019
}

The Indian subcontinent (a loose term comprising of India, Nepal, Bangladesh, Pakistan, Nepal, Srilanka, Bhutan and the Maldives) is home to more than 1.5 billion people (with more than 1.3 billion in India alone) as per the latest World Bank estimates [1]. This accounts for nearly a fifth of the worlds population. The population here is mainly "young" with more than $65 \%$ of the population below the age of 35 . The median age is expected to be 29 years by the year 2020 [1].

It is a diverse area with wide variations in race, ethinicity, socioeconomic status, religion, language and cultural practices across the region [2]. It is also an area of rapidly changing demographics. Life expectancy in the region is also gradually increasing from around 36 years in 1947 and is currently around 67 years [1]. There is an increae in urbanisation across the region, with only $11 \%$ of the population living in cities at the turn of the 20th century, but increasing to more than $30 \%$ a century later [2].

With this increasing urbanisation, improving economic status, changing lifestyles and increasing life expectancy, comes increasing incidence of chronic illnessness such as diabetes, hypertension and cardiovascular diseases [3]. Studies have shown that the prevalence of diabetes and hypertension is increasing in the region $[4,5]$. Recent data suggest that the prevalence of diabetes in the adult population in India is around $8.8 \%$ as a whole [6], though in some urban areas it is as high as $17 \%$ [7]. The prevalence of hypertension is much higher and currently is around 33\% for the whole of south asia [8], and specifically around 33\% in urban india and $25 \%$ in rural india [9]. The reasons for this increase are multifactorial. Changing lifestyles leading to a more sedentary behaviour could be a major factor. It is also likely that improved access to health care leads to

Sunil K Nadar

sunilnadar@gmail.com

1 Sultan Qaboos University Hospital, Department of Cardiology, Muscat, Oman higher detection and hence higher reporting of these hitherto undiagnosed and unreported conditions. Indeed studies have shown that even in the rural areas the incidence of hypertension is increasing and this could be a combination of all the above factors and not least due to improved access to health care [10].

Bearing this is mind, the Journal of Human Hypertension has decided to bring out this special spotlight issue on hypertension in the India. In this issue we look at the various aspcects of hypertension in the subcontinent. Gupta et al. [11] and Ghimire et al. [12] describe the current epidemiology of hypertension in India and Nepal respectively. Gupta et al. [11] especially point out the increasing incidence of hypertension even with in the rural populations, where previously, the incidence of hypertension and other non communicable diseases were traditionally lower than the urban populations. Similarly in Nepal, Ghimire et al. [12] found that hypertension and other cardiovascular risk factors appear to be increasing in the elderly population. They have studied the various aspects of risk factors in this elderly population.

The hypertension society of India, along with their sister organisations the Association of Physicans of India, and the Cardiology society of India have published guidelines for the management of hypertension in the Indian setting with the latest (third) guidelines [13] published in 2013. Due to lack of sufficient local studies, guidelines in many countries often base their recommendations on western guidelines but modified according to local conditions [14]. The latest American guidelines [15] caused much controversy with regards to their new diagnostic criteria, but the European guidelines [16] kept them relatively unchanged. Therefore we would expect new Indian guidelines sometime in the near future with their recommendations for the indian population. The new American and European guidelines also attach much importance to risk stratification and the use of risk stratification models which are lacking in the Indian population. In this issue, Wander et al. [17] discuss the applicability of western guidelines in the Indian setting, 
the need for modification of these guidelines to suit local requirements and the need for a local risk stratification model.

Like Hypertension, the incidence of diabetes is also increasing at an alarming rate [6]. Hypertension often coexists in diabetics. Tighter control of blood pressure is essential in diabetic patients $[15,16]$. Viswanathan et al. [18] study the scope of blood pressure control in diabetic patients in India and the challenges faced by physicians to attain optimal blood control in these patients.

In addition to cardiovascular complications, hypertension is also associated with microvascular and macrovscular cerbrovascular disease. Dementia or cognitive impairment is an important microvascular complication of hypertension, which could be due to white matter changes as a result of microvascualr disease [19]. Hypertension is also a major risk factor for strokes and cognitive impairment is common after strokes [20]. Good blood pressure control has been shown to delay the progression of dementia [21], although the recent SPRINT-MIND trial did not show a statistical benefit of intensive BP control [22]. In this special issue Nair et al. [23] explore the risk of dementia in hypertensive patients in India and the management of these patients in the indian setting.

In a vast country like India where majority of the population live in rural areas, delivery of care is often a problem [24]. Coupled with low socioeconomic status and low literacy levels, health education programmes may not have the intended effect and government led healthcare programmes may not reach the people that it is intended to reach. Sharma et al. [25] from the public health foundation of India discuss a new strategy of providing education to primary care physicians in the rural setting and proving that this improves patient care. Some of the other topics covered in this spotlight include seasonal variation in blood pressure in India [26], and the role of repeated blood pressure measurements in the indian setting [27].

The editorial board of the Journal of Human Hypertension hope that this special India spotlight issue would help to focus attention on the emerging problem of hypertension in the subcontinent. We hoep it would help raise awareness of the magnitude of the problem, the various obstacles involved in the implementation and delivery of healthcare and help to provide some solution to these issues.

\section{References}

1. World Bank in India. 2019 https://www.worldbank.org/en/ country/india. Accessed 6 June 2019.

2. Demographics in India. 2019. http://worldpopulationreview.com/ countries/india-population/. Accessed 6 June 2019.
3. Global, regional, and national comparative risk assessment of 84 behavioural, environmental and occupational, and metabolic risks or clusters of risks, 1990-2016: a systematic analysis for the Global Burden of Disease Study 2016. Lancet. 2017;390: 1345-422.

4. Gupta R. Trends in hypertension epidemiology in India. J Hum Hypertens. 2004;18:73-8.

5. The increasing burden of diabetes and variations among the states of India: the Global Burden of Disease Study 1990-2016. Lancet Glob Health. 2018;6:e1352-e1362.

6. International Diabetes Federation. 2019. https://www.idf.org/ournetwork/regions-members/south-east-asia/members/94-india.html Accessed 6 June 2019.

7. Tripathy JP, Thakur JS, Jeet G, Jain S. Prevalence and determinants of comorbid diabetes and hypertension: Evidence from non communicable disease risk factor STEPS survey, India. Diabetes Metab Syndr. 2017;11(Suppl 1):S459-S465.

8. Beaney T, Burrell LM, Castillo RR, Charchar FJ, Cro S, Damasceno A, et al. May Measurement Month 2018: a pragmatic global screening campaign to raise awareness of blood pressure by the International Society of Hypertension. Eur Heart J. 2019;21 (Suppl D):D14-D16.

9. Anchala R, Kannuri NK, Pant H, Khan H, Franco OH, Di AE, et al. Hypertension in India: a systematic review and meta-analysis of prevalence, awareness, and control of hypertension. J Hypertens. 2014;32:1170-7.

10. Gupta R. Convergence in urban-rural prevalence of hypertension in India. J Hum Hypertens. 2016;30:79-82.

11. Gupta R. Emerging trends in hypertension epidemiology in India. J Hum Hypertens. 2019.

12. Ghimire S. Noncommunicable disease risk factors among older adults aged 60-69 years in Nepal: findings from The STEPS Survey 2013. J Hum Hypertens. 2019.

13. Indian guidelines on hypertension-(IGH)-III; 2013. J Assoc Physicians India. 2019:61 2Suppl:6-36.

14. Home P, Haddad J, Latif ZA, Soewondo P, Benabbas Y, Litwak $\mathrm{L}$, et al. Comparison of national/regional diabetes guidelines for the management of blood glucose control in non-western countries. Diabetes Ther. 2013;4:91-102.

15. Whelton PK, Carey RM, Aronow WS, Casey DE Jr., Collins KJ, Dennison HC, et al. 2017 ACC/AHA/AAPA/ABC/ACPM/AGS/ $\mathrm{APhA} / \mathrm{ASH} / \mathrm{ASPC} / \mathrm{NMA} / \mathrm{PCNA}$ guideline for the prevention, detection, evaluation, and management of high blood pressure in adults: a report of the American College of Cardiology/American Heart Association Task Force on Clinical Practice Guidelines. Hypertension. 2018;71:e13-e115.

16. Williams B, Mancia G, Spiering W, Agabiti RE, Azizi M, Burnier $\mathrm{M}$, et al. $2018 \mathrm{ESC} / \mathrm{ESH}$ Guidelines for the management of arterial hypertension. Eur Heart J. 2018;39:3021-104.

17. Wander G. Western guidelines bring in cardiovascular risk prediction along with blood pressure levels for initiation of antihypertensive drugs: Is the pitch ready for Indians. J Hum Hypertens. 2019.

18. Viswanathan V. Blood pressure control in diabetes-the Indian perspective. J Hum Hypertens. 2019.

19. Kennelly SP, Lawlor BA, Kenny RA. Blood pressure and dementia - a comprehensive review. Ther Adv Neurol Disord. 2009;2:241-60.

20. Sun JH, Tan L, Yu JT. Post-stroke cognitive impairment: epidemiology, mechanisms and management. Ann Transl Med. 2014;2:80.

21. Tzourio C, Anderson C, Chapman N, Woodward M, Neal B, MacMahon S, et al. Effects of blood pressure lowering with perindopril and indapamide therapy on dementia and cognitive decline in patients with cerebrovascular disease. Arch Intern Med. 2003;163:1069-75. 
22. Williamson JD, Pajewski NM, Auchus AP, Bryan RN, Chelune G, Cheung AK, et al. Effect of Intensive vs Standard Blood Pressure Control on Probable Dementia: A Randomized Clinical Trial. J Am Med Assoc. 2019;321:553-61.

23. Nair T. Challenges of hypertension and dementia in the indian subcontinent, a review. J Hum Hypertens. 2019.

24. Kasthuri A. Challenges to healthcare in India-the five A's. Indian J Community Med. 2018;43:141-3.
25. Sharma A. collaborative model for capacity building of primary care physicians in the management of Hypertension in India. $\mathrm{J}$ Hum Hypertens. 2019.

26. Goyal A. Seasonal variation in $24 \mathrm{~h}$ blood pressure profile in healthy adults - a prospective observational study. J Hum Hypertens. 2019.

27. Jose AP. Impact of repeated blood pressure measurement on blood pressure categorization in a population-based study from India. J Hum Hypertens. 2019. 